\title{
Neue, von den Herren Otto Leonhard und M. Hilf in der Herzegowina entdeckte Grottenkäfer.
}

\author{
Beschrieben von Edm. Reitter in Paskau (Mähren).
}

Leonhardella nov. gen. Pholeuonidarum.

Mit Leonhardia Rttr. W. 1901, 128, sehr nahe verwandt, aber der Thorax ist quer, an den Seiten stumpf gewinkelt, der Mesosternalkiel groß, vorn rechteckig abgeschnitten, nicht hakenförmig; die Vorderfüße sind in beiden Geschlechtern 4-gliedrig und durchaus einfach und gleichartig, endlich durch die Sexualauszeichnungen, welche im Baue der Fühler zur Geltung kommen, verschieden. Die Fühler sind lang, beim $q$ ist das 8 . Glied wenig länger als breit und klein, das letzte nicht ganz so lang als die 2 vorhergehenden zusammen, einfach; beim $\sigma^{\Upsilon}$ sind die Fühler noch länger, die Glieder gestreckter, das schmächtigere Glied 8 ist länglich und wenig kürzer als 9, das Endglied ist langgestreckt, ringsum dichter behaart, hinter der Basis breit und flach eingeschnürt.

\section{Leonhardella angulicollis n. sp.}

Rostroth, Oberseite sehr fein und dicht gelblich anliegend behaart. Fühler die Mitte des Körpers sehr weit überragend, schlank. Kopf viel schmäler als der Halsschild, klein; ohne Augen. Letztes Glied der Maxillartaster klein, dünn zugespitzt, halb so lang als das leicht verdickte vorletzte. Halss child quer, viel breiter als lang, aber schmäler als die Basis der Flügeldecken, die Seiten von der Mitte zur Basis zur Artikulation der Vorderschenkel, sehr stark ausgeschweift, dicht vor der Mitte stark gewinkelt, der Winkel selbst abgerundet, von da zur Spitze stark, fast gerade verengt, Vorderrand breit und flach ausgebuchtet, die Vorderecken etwas spitzig nach vorne vortretend, die Basis bis gegen die Hinterecken fast gerade, die letzteren lang und spitzig nach außen und gleichzeitig ein wenig hinten über die Basis gezogen, aber die stumpfen Schulterwinkel der Deckenbasis nicht erreichend. Oberseite außerordentlich dicht und fein punktulirt. Schildchen groß, dreieckig. Flügeldecken ziemlich kurz und breit eiförmig, viel breiter als der Thorax, beim or wenig vor, beim $q$ fast hinter der Mitte am breitesten, außerordentlich dicht und fein punktulirt, dazwischen hautartig chagrinirt, ohne Suturalstreifen, der 
Seitenrand als feine aufgebogene Leiste von obenher sichtbar, die Spitze einzeln stumpf abgerundet, besonders beim $q$ das Pygidium nicht vollständig bedeckend. Beine dünn und lang, die Schenkel stärker als die Schienen, zur Spitze etwas verjüngt, die vordersten kaum stärker als die andern, unter den Thorax nicht einlegbar, die Schienen gerade, unbedornt, die Tarsen kürzer als die Schienen, dünn, einfach, 5-gliedrig, die Vordertarsen einfach, in beiden Geschlechtern viergliederig, das erste Glied aller Tarsen gestreckt. Klauen dünn und zart. Long. $3 \cdot 4-3 \cdot 8 \mathrm{~mm}$.

Herzegowina. Von meinem lieben Freunde Otto Leonhard in Anzahl aus einer Grotte am Lebršnik, bei Gacko, mitgetheilt, die im Juli d. J. gesammelt wurden. Ich kann mir nicht versagen, auch diese Gattung nach dem Entdecker zu benennen, zum Zeichen meines Dankes für seine Liberalität, ferner als Anerkennung seiner vieljährigen erfolgreichen Forschungen im Occupationsgebiete, endlich will ich durch den Gattungsnamen andeuten, daß diese neue Gattung mit Leonhardia in naher Beziehung steht.

Silphanillus nov. gen. Pholeuonidarum.

Mit Pholeuonopsis Apfelb. sehr nahe rerwandt; von dieser Gattung zu unterscheiden durch langgestreckte flache Gestalt, nicht glockenförmigen Thorax, vorne schmälere, normale Epipleuren der Flügeldecken, durch die Bildung der Mittel- und Vorderbrust, und gerade (nicht wie dort gebogene), außen fein bedornte Mittelschienen.

Der Mesosternalkiel ist hoch, hakenförmig, die Vorderbrust nicht erreichend, der Vorderrand der Mittelbrust gerade abgeschnitten, die Mitte vom Hakenzahne bis zum Vorderrande dachförmig gehoben und die Kante fein doppelkielig markirt, der vordere Theil der Mittelbrust bis zum Hakenzahne des hohen Kieles ist durch eine geschwungene Linie abgegrenzt, die Fläche dieses vorderen Mittelbrusttheiles ist in der Mitte ziemlich breit und mündet seitlich in einer Spitze aus; die Mitte der Vorderbrust wird nicht ganz von den Gelenkgruben der Vorderhüften ausgefüllt, der Basalrand ist wenig nach innen abgeschrägt und zeigt in der Mitte einen conischen Schlitz zur Aufnahme der doppelkieligen Spitze des Mesosternalvorderrandes; die Abgrenzungslinie der Mittelbrust von der Hinterbrust ist von den Trochantinen der Nittelhüften nach außen horizontal und gerade.

Bei Pholeuonopsis ist der hakenförmige Mesosternalkiel vorne zum Körper abgeschrägt und dem Vorderrande der Mittelbrust mehr genähert, der letztere ist gerundet, die Mitte schwach dachförmig 
gehoben, der vordere Theil der Mittelbrust vom Hakenkiele zum Vorderrande ist schmal und die diesen Theil abgrenzende Linie verlauft parallel mit dem Vorderrande schräg gerundet nach vorne und ist überall gleich schmal, eine dicke Randung bildend. Die Mitte der Vorderbrust ist sehr schmal, nachdem die Basis derselben sich sehr stark nach innen abschrägt, die Gelenkhöhlen der Vorderhüften füllen deshalb den ganzen mittleren Raum aus, der Basalrand lauft in der Mitte winkelig zusammen; die Abgrenzungslinie der Mittelbrust von der Hinterbrust stark schräg nach vorne gerichtet.

\section{Silphanillus Leonhardi n. sp.}

Lang oval, oben abgeflacht, glänzend gelbroth, oben fein und anliegend gelb behaart. Fühler kräftig, die Mitte des Körpers überragend, die letzten 5 Glieder mit Ausnahme von Glied 8, das nicht länger als breit ist und klein, etwas verbreitert, das letzte Glied ist beim $q$ nicht länger als das vorhergehende. Glied 1 etwa doppelt so breit als lang, kürzer als 2, 3 und 5 gleich lang, länger als 4 und kürzer als 2; Glied 4 und 1 von gleicher Länge. Kopf klein, viel schmäler als der Thorax, ohne Augen, oben sehr erloschen, kaum erkennbar punktulirt. Halsschild etwas breiter als lang, die Basis schwach doppelbuchtig und viel breiter als der fast gerade abgestutzte Vorderrand, die Seiten in der Mitte gerundet und hier so breit als die Basis sammt den Hinterwinkeln, die Seiten sind kantig abgegrenzt, von der Mitte nach vorne stärker verengt, zur Basis ausgebuchtet (geschwungen), die Hinterwinkel spitzig nach hinten und außen, aber schwach, vorgezogen, die Scheibe ist äußerst fein und dicht punktulirt und am Grunde, bei starker Vergrößerung erkennbar, chagrinirt. Schildchen dreieckig, normal entwickelt, punktulirt. Flügeldecken etwas, aber deutlich breiter an der Basis als der Halsschild, langgestreckt, an den Seiten fast parallel und erst hinter der Vitte zur Spitze gerundet verengt, der Seitenrand schmal abgesetzt und deutlich, scharf aufgebogen, die Randkante von obenher übersehbar, mit feinen abstehenden, nach hinten geneigten, wenig dichten Härchen bewimpert, die Basis fast gerade, der Schulterwinkel stumpf vortretend, fast rechteckig, die Scheibe ohne Streifen, die Naht nicht eingesenkt, ziemlich stark und mäßig dicht punktirt, die Punkte haben die Neigung, sich quer, unregelmäßig aneinander zu gruppiren und sind etwas raspelartig, die Punktirung hinten feiner und rarer werdend und erlischt an der Spitze fast vollständig. Oberseite der Flügeldecken außer der feinen, anliegenden Behaarung noch mit längeren, besonders 
zur Spitze deutlicheren aufgerichteten, nach hinten geneigten Haaren besetzt, wodurch sich diese Gattung auszeichnen dürfte. Die Py gidiumspitze ist frei. Beine mäßig lang, von gewöhnlicher Form, die Schenkel zur Spitze verdünnt, die Schienen, auch die mittleren, gerade (†) und die hinteren, die mittleren deutlicher, mit starren Härchen, dörnchen-

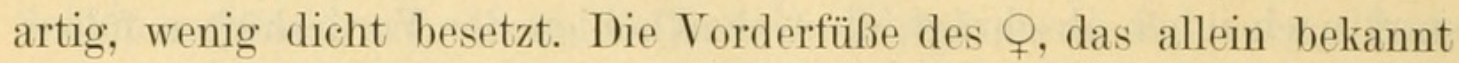
ist, 4 gliedrig. Long. $4 \mathrm{~mm}$.

Herzegowina. Auf der höchsten Stelle des Vlasulja (wo auch Anophthalmus Speiseri vorkommt) unter einem tief eingebetteten Steine aufgefunden und mir von Herrn Otto Leonhard (Blasewitz) freundlichst zur Beschreibung mitgetheilt. (1 †.) — Wahrscheinlich dürfte das prächtige Thier normal in den nahen Grotten der Fundstelle zu finden sein.

\section{Anophthalmus Hilfi n. sp.}

Eine prächtige, sehr große Art, aus der Verwandschaft des A. Schmidti und Schanmi, die sich schon durch die doppelte Größe und flache Körperform weit entfernt.

Rostroth, glänzend, außer den normalen Tasthaaren kahl. Die Fühler sehr lang, $3 / 4$ der Länge des Körpers erreichend, Glied 2 viel kürzer als 3, von der Mitte des zweiten Gliedes an pubescent. Kopf groß, sehr wenig schmäler als der Thorax, ganz ohne Augenfacetten, von normaler Form, die Frontalfurchen hinten flach, nach außen förmlich erloschen, in der Mitte gebuchtet, daselbst einander mehr genähert. Halsschild so lang als breit, viel schmäler als die Flügeldecken, im vordersten Viertel am breitesten, von da fast in gerader Linie zu den Hinterwinkeln verengt, diese kurz und spitzig nach außen vortretend, vor ihnen der Seitenrand kaum ausgeschweift, Vorder- und Hinterrand fast gerade abgestutzt, der erstere höchstens mit der Spur einer breiten und flachen Ausbuchtung, die Scheibe leicht gewölbt, die Mittellinie kräftig, an der vertieften, matteren microscopisch fein gestrichelten Basis, verkürzt, die Basalstriche kurz, mäßig tief, grübchenförmig; ein borstentragender Punkt steht wie gewöhnlich in der Nähe der Hinterwinkel und ein anderer am Seitenrande weit vor der Mitte; der Seitenrand ist schmal und fast gleichmäßig abgesetzt und aufgebogen. Flügeldecken ziemlich breit, oval, sehr flach gewölbt, die Schulterwinkel abgerundet, nur mit angedeutetem sehr stumpfem Winkel, der Seitenrand schmal abgesetzt, aber gleichmäßig hoch aufgebogen. Oberseite mit sehr feinen Punktstreifen, dieselben zur Naht allmälig deutlicher ausgeprägt, die inneren 5 voll- 
ständig, die äußeren mehr oder minder nur angedeutet, im 3. stehen 3 Borstenpunkte, an der Basis der 7. einer, außerdem hat der 8. die normalen Seitenpunkte der series umbilicata; der umgebogene Apicalstreif bleibt im Niveau des hinteren, dritten Borstenpunktes. Beine lang und schlank, die Vorderschienen mit etwas abgeflachter, matterer Kante ihres schmalen Außenrandes, die nach innen etwas kantig begrenzt erscheint. Die Tarsen dicht behaart, das vorletzte Glied an der Spitze der Unterseite viel länger behaart. Die ganze Oberseite ist am Grunde sehr fein hautartig chagrinirt. Long. $9.5 \mathrm{~mm}$.

Herzegowina. Ein $q$ wurde von Herrn M. Hilf und Herrn Otto Leonhard in der Höhle »Bukova rupa pod Jastrebica «, in 1200 Meter Höhe bei Ubli, hart an der montenegrinischen Grenze, durch Köderung gefangen. Hoffentlich gelingt es unserem unermüdlichen Erforscher der Herzegowina, Herrn O. Leonhard, weitere Stücke dieser größten Art aufzufinden.

\section{Uebersicht der Otiorrhynchus-Arten aus der Untergattung Limatogaster Apfelb. ${ }^{*}$ (Coleoptera.)}

Von Edm. Reitter in Paskau (Mähren.)

(Otiorrhynchus rugicollis Germ. und Verwandte.)

1" Fühler kräftig, mäßig dick, die Glieder der Geißel niemals länger als breit, die Keule nicht doppelt so breit als die letzteren.

Die pupillirten Tuberkeln des Halsschildes auf der Scheibe fast der Länge nach zusammengeflossen, die Flügeldecken länglicheiförmig, beim $q$ etwas kürzer und breiter, die längere Zwischenbehaarung wenig lang, stark geneigt, Beine robust, fast anliegend behaart, der Zahn aller Schenkel stark entwickelt. Long. $6-7 \cdot 5 \mathrm{~mm}$. - Dalmatien, Herzegowina, Bosnien, Croatien und angeblich auch in Ungarn.

rugicollis Germ.

1' Fühler schlank und dünn, rostroth, die Keule doppelt so breit als die niemals queren äußeren Geißelglieder.

2" Fühlerschaft und Beine anliegend oder fast anliegend behaart, die Behaarung nur auf der Hinterseite der Mittel- und Hinterschienen manchmal etwas abstehend und geneigt, die längeren Härchen derFlügeldecken gekrümmt, selten fehlt diese längere Zwischenbehaarung ganz.

*) Wiss. Mitth. aus Bosn. Herzeg., Wien 1899. 758.

Wiener Entomologische Zeitung, XXII. Jahrg., Heft VII und VIII (5. Sept 1903). 


\section{$2 \mathrm{BHL}$ Biodiversity Heritage Library}

Reitter, Edmund. 1903. "Neue, von den Herren Otto LEONHARD und M. HILF in der Herzegowina entdeckte Grottenkäfer." Wiener entomologische Zeitung 22, 209-213. https://doi.org/10.5962/bhl.part.9742.

View This Item Online: https://www.biodiversitylibrary.org/item/43794

DOI: https://doi.org/10.5962/bhl.part.9742

Permalink: https://www.biodiversitylibrary.org/partpdf/9742

\section{Holding Institution}

Smithsonian Libraries

\section{Sponsored by}

Smithsonian

\section{Copyright \& Reuse}

Copyright Status: NOT_IN_COPYRIGHT

This document was created from content at the Biodiversity Heritage Library, the world's largest open access digital library for biodiversity literature and archives. Visit BHL at https://www.biodiversitylibrary.org. 